\title{
Antimicrobial susceptibility pattern of bacterial isolates from wound infection and their sensitivity to alternative topical agents at Jimma University Specialized Hospital, South-West Ethiopia
}

Mohammedaman Mama', Alemseged Abdissa ${ }^{2}$ and Tsegaye Sewunet ${ }^{2^{*}}$

\begin{abstract}
Background: Wound infection is one of the health problems that are caused and aggravated by the invasion of pathogenic organisms. Information on local pathogens and sensitivity to antimicrobial agents, and topical agents like acetic acid is crucial for successful treatment of wounds.

Objectives: To determine antimicrobial susceptibility pattern of bacterial isolates from wound infection and their sensitivity to alternative topical agents at Jimma University Specialized Hospital.

Methods: A cross sectional study was conducted among patients with wound infection visiting Jimma University Specialized Hospital, from May to September 2013. Wound swab was collected using sterile cotton swabs and processed for bacterial isolation and susceptibility testing to antimicrobial agents, acetic acid, hydrogen peroxide and dabkin solution following standard bacteriological techniques. Biochemical tests were done to identify the species of the organisms. Sensitivity testing was done using Kirby- Baur disk diffusion method. Minimum inhibitory and bactericidal concentration was done using tube dilution method.

Results: In this study 145 bacterial isolates were recovered from 150 specimens showing an isolation rate of $87.3 \%$. The predominant bacteria isolated from the infected wounds were Staphylococcus aureus 47 (32.4\%) followed by Escherichia coli 29 (20\%), Proteus species 23 (16\%), Coagulase negative Staphylococci 21 (14.5\%), Klebsiella pneumoniae 14 (10\%) and Pseudomonas aeruginosa 11 (8\%). All isolates showed high frequency of resistance to ampicillin, penicillin, cephalothin and tetracycline. The overall multiple drug resistance patterns were found to be $85 \%$. Acetic acid (0.5\%), Dabkin solution (1\%) and 3\% hydrogen peroxide were bactericidal to all isolated bacteria and lethal effect observed when applied for 10 minutes.
\end{abstract}

Conclusions: On in vitro sensitivity testing, ampicillin, penicillin, cephalothin and tetracycline were the least effective. Gentamicin, norfloxacin, ciprofloxacin, vancomycin and amikacin were the most effective antibiotics. Acetic acid (0.5\%), dabkin solution (1\%) and $\mathrm{H}_{2} \mathrm{O}_{2}(3 \%)$ were bactericidal to all isolates.

Keywords: Bacterial pathogens, Drug resistance, Wound infection, Jimma, Ethiopia

\footnotetext{
* Correspondence: tsegishs2010@gmail.com

${ }^{2}$ Department of Medical Laboratory Science and Pathology, Jimma

University, Jimma, Ethiopia

Full list of author information is available at the end of the article
} 


\section{Introduction}

The primary function of intact skin is to control microbial populations that live on the skin surface and to prevent underlying tissue from becoming colonized and invaded by potential pathogens [1].

Exposure of subcutaneous tissue following a loss of skin integrity (i.e. wound) provides a moist, warm, and nutritious environment that is conducive to microbial colonization and proliferation. Since wound colonization is most frequently poly-microbial, involving numerous microorganisms that are potentially pathogenic, any wound is at some risk of becoming infected [2].

Infection in wound constitutes a major barrier to healing and can have an adverse impact on the patient's quality of life as well as on the healing rate of the wound. Infected wounds are likely to be more painful, hypersensitive and odorous, resulting in increased discomfort and inconvenience for the patient [3].

The prevalent organisms that have been associated with wound infection include Staphylococcus aureus (S. aureus) which from various studies have been found to account for $20-40 \%$ and Pseudomonas aeruginosa (P. aeruginosa) $5-15 \%$ of the nosocomial infection, with infection mainly following surgery and burns. Other pathogens such as Enterococci and members of the Enterobacteriaceae have been implicated, especially in immune compromised patients and following abdominal surgery [4].

Wound healing needs a good healthy environment so that the normal physiological process will result in a normal healing process with minimal scar formation. One of the most important strategies to keep the process of healing ongoing is to sterilize damaged tissue from any microbial infection [5].

Continued use of systemic and topical antimicrobial agents has provided the selective pressure that has led to the emergence of antibiotic resistant strains which in turn, has driven the continued search for new agents. Unfortunately, the increased costs of searching for effective antimicrobial agents and the decreased rate of new drug discovery has made the situation increasingly worrisome [6].

Hence the present study is designed to update profile of bacteria present in wounds, their sensitivity to antibiotics and sensitivity to alternative topical agents at Jimma University Specialized Hospital, Jimma, Ethiopia.

\section{Methods}

\section{Study design and area}

A cross sectional study was conducted at Jimma University specialized hospital (JUSH), which is located $354 \mathrm{Km}$ away from Addis Ababa, South West, Ethiopia, from May to September 2013. JUSH is a referral hospital in southwestern part of the country.

\section{Sampling procedure}

A questionnaire was used to obtain data from the patient after obtaining an informed consent from the patient/ guardians. Open wound swabs were aseptically obtained after the wound immediate surface exudates and contaminants were cleansed off with moistened sterile gauze and sterile normal saline solution. Dressed wounds were cleansed with sterile normal saline after removing the dressing. The specimen was collected on sterile cotton swab by rotating with sufficient pressure. Double wound swabs were taken from each wound at a point in time to reduce the chance of contamination. The samples were transported to the laboratory after collection using Amies transport media.

\section{Culture and identification}

Swabs collected were streaked on blood agar and $\mathrm{MaC}$ conkey agar (oxoid) by sterile inoculation loop. The plates were incubated at $35-37^{\circ} \mathrm{C}$ for $24-48$ hours. Preliminary identification of bacteria was based on colony characteristics of the organisms. Such as haemolysis on blood agar, changes in physical appearance in differential media and enzyme activities of the organisms. Biochemical tests were performed on colonies from primary cultures for identification of the isolates. Gram-negative rods were identified by performing a series of biochemical tests (oxoid). Namely: Kliger Iron Agar (KIA), Indole, Simon's citrate agar, Lysine Iron Agar (LIA), urea and motility. Gram-positive cocci were identified based on their gram reaction, catalase and coagulase test results.

\section{Antibacterial susceptibility testing (AST)}

Susceptibility testing was performed by Kirby-Bauer disk diffusion technique according to criteria set by CLSI 2011. The inoculum was prepared by picking parts of similar test organisms with a sterile wire loop and suspended in sterile normal saline. The density of suspension to be inoculated was determined by comparison with opacity standard on McFarland 0.5 Barium sulphate solution. The test organism was uniformly seeded over the Mueller-Hinton agar (oxoid) surface and exposed to a concentration gradient of antibiotic diffusing from antibiotic-impregnated paper disk into the agar medium, and then incubated at $37^{\circ} \mathrm{C}$ for $16-18$ hours. Diameters of the zone of inhibition around the discs were measured to the nearest millimeter using a ruler and classified as sensitive, intermediate, and resistant according to the standardized table supplied by CLSI 2011.

The drugs tested for both gram negative and gram positive bacteria were ampicillin $(10 \mu \mathrm{g})$, ciprofloxacin $(5 \mu \mathrm{g})$, norfloxacin $(10 \mu \mathrm{g})$, cephalothin $(30 \mu \mathrm{g})$, gentamicin $(10 \mu \mathrm{g})$, tetracycline $(30 \mu \mathrm{g})$, cotrimoxazole $(25 \mu \mathrm{g})$, chloramphenicol $(30 \mu \mathrm{g})$, doxycycline $(30 \mu \mathrm{g})$, naldixic acid $(15 \mu \mathrm{g})$ and ceftriaxone $(30 \mu \mathrm{g})$. Penicillin G (10 IU), 
erythromycin $(15 \mu \mathrm{g})$ and vancomycin $(30 \mu \mathrm{g})$ were used for only gram positive bacterial isolates (oxoid). These antimicrobial selected based on the availability and prescription frequency of these drugs in the study area.

\section{Minimum inhibitory and bactericidal concentration determination}

Freshly prepared solutions of different concentrations $0.5 \%, 1 \%, 1.25 \%, 1.5 \%, 1.75 \%$ and $2 \%$ of acetic acid was prepared by adding in to $100 \mathrm{ml}$ of sterile distilled water, while $(0.025 \%, 0.25 \%, 0.5 \%, 1 \%, 1.25 \%, 1.5 \%, 1.75 \%$ and $2 \%$ concentration of dabkin solution were made by adding in to $100 \mathrm{ml}$ of sterile distilled water. Hydrogen peroxide (3\%) was used. The minimum inhibitory concentrations (MICs) and minimum bactericidal concentrations (MBCs) of the antimicrobial agents were determined for each isolate by tube dilution method then sub cultured on agar plate. This technique was done by mixing sterile $4.9 \mathrm{ml}$ of tryptone soya broth (oxoid) with $5 \mathrm{ml}$ of each serially obtained concentration of antimicrobial agents. The test organisms from growth on nutrient agar plates incubated at $37^{\circ} \mathrm{C}$ for $18 \mathrm{hrs}$ were suspended in sterile saline solution and adjusted to match a turbidity of 0.5 McFarland standards. To get a final volume of $10 \mathrm{ml}, 0.1 \mathrm{ml}$ of standardized bacterial suspension was inoculated in each tube. After overnight incubation aerobically at $36-37^{\circ} \mathrm{C}$ the tubes were examined macroscopically for visible evidence of bacterial growth in the form of turbidity by comparing with the control tubes. Two control tubes were employed; one was a row of positive control tubes containing only the nutrient broth and each of the microorganisms, while negative controls were set up as follows: nutrient broth only; nutrient broth and sterile antimicrobial agents. MIC was recorded as the lowest concentration of dabkin solution or acetic acid that inhibited bacterial growth (no visible growth or turbidity). The minimum bactericidal concentration were determined from the test tubes used in the determination of MIC, the tubes that showed no visible growth were sub cultured onto freshly prepared nutrient agar at $37^{\circ} \mathrm{C}$ for 48 hours. Plates were examined and $\mathrm{MBC}$ was recorded as the lowest concentration of dabkin solution and acetic acid at which no colony was formed on the plate.

\section{Data analysis}

Data was edited, cleaned, entered and analyzed using statistical package for social science (SPSS) version 17. Descriptive analysis such as frequencies and mean were used. The chi-square test was employed to compare the association of socio-demographic data, wound type, location with wound infection status of the patients. P-value of $<0.05$ was considered to indicate statistically significant differences. The result was presented using tables and charts.

\section{Ethics}

Ethical clearance was obtained from the ethical committee of Jimma University college of Public Health and Medical Science. Written informed consent was obtained from all study participants.

\section{Results}

A total of 150 specimens were collected from patients with clinical evidence of wound infection (patients with complaints of discharge, pain, swelling, foul smelling and chronic wound) from May to September, 2013. The subjects included 107 (71.3\%) males and 43 (28.7\%) females. The ages of the patients ranged from 6 months to 90 years with mean age of $31.68 \pm 17.12$ (Table 1 ).

Forty five (30\%) samples screened was obtained from the leg, while $22(14.7 \%)$ of the wound affected the abdomen. Sixty five of the cases $(43.3 \%)$ seen were trauma, followed by $34(22.7 \%)$ which were postoperative wound (Table 2).

\section{Bacterial profile}

Of the 150 swabs 131 (87.4\%) were culture positive for bacterial pathogens, while 19 (12.6\%) were bacteriologically sterile. The presence of only one species isolated from each sample was the most frequent (91.6\%) while, more than one species were isolated from (8.4\%) of the total swabs. A total of 145 bacterial isolates were obtained, 77 (53\%) were gram negative while 68 (47\%) were gram positive. S. aureus was the predominant organism isolated 47 (32.4\%), followed by Escherichia coli (E. coli) 29 (20\%), Proteus spps 23 (16\%), coagulase negative Staphylococci 21 (14.5\%), Klebsiella pneumoniae (K. pneumoniae) $14(10 \%)$ and P. aeruginosa 11 (8\%) (Figure 1).

Table 1 Wound infection and socio-demographic characteristics of the patients at JUSH, Jimma, May-September, 2013

\begin{tabular}{llll}
\hline Demographic characters & $\begin{array}{l}\text { Infected } \\
\text { No. (\%) }\end{array}$ & $\begin{array}{l}\text { Not infected } \\
\text { No. (\%) }\end{array}$ & $\begin{array}{l}\text { Total } \\
\text { No. (\%) }\end{array}$ \\
\hline Sex & $96(89.7)$ & $11(10.3)$ & $107(71.3)$ \\
Male & $35(81.4)$ & $8(18.6)$ & $43(28.7)$ \\
Female & $\mathbf{1 3 1 ( 8 7 . 3 )}$ & $\mathbf{1 9 ( 1 2 . 7 )}$ & $\mathbf{1 5 0 ( 1 0 0 )}$ \\
Total & & & \\
Age in years & $21(87.5)$ & $3(12.5)$ & $24(16)$ \\
$\leq 15$ & $54(87.1)$ & $8(13)$ & $62(41.3)$ \\
$16-30$ & $25(86.2)$ & $4(13.8)$ & $29(19.3)$ \\
$31-44$ & $17(89.5)$ & $2(10.5)$ & $19(12.7)$ \\
$45-59$ & $14(87.5)$ & $2(12.5)$ & $16(10.7)$ \\
$\geq 60$ & $\mathbf{1 3 1 ( 8 7 . 3 )}$ & $\mathbf{1 9 ( 1 2 . 7 )}$ & $\mathbf{1 5 0 ( 1 0 0 )}$ \\
Total & &
\end{tabular}


Table 2 Wound type and location from patients with infected wounds at JUSH, Jimma, May-September 2013

\begin{tabular}{ll}
\hline Wound location & Number (\%) \\
\hline Leg & $45(30.0)$ \\
Abdomen & $22(14.7)$ \\
Hand & $13(8.7)$ \\
Buttocks & $13(8.7)$ \\
Foot & $13(8.7)$ \\
Head and neck & $12(8.0)$ \\
Back & $11(7.3)$ \\
Genitals & $8(5.3)$ \\
Breast and chest & $7(4.7)$ \\
Armpit & $3(2.0)$ \\
Others & $3(2.0)$ \\
Total & $150(100.0)$ \\
Type of wound & \\
Trauma & $65(43.3)$ \\
Postoperative wound & $34(22.7)$ \\
Abcess & $31(20.7)$ \\
Ulcers & $10(6.7)$ \\
Burn wound & $5(3.3)$ \\
Diabetic foot ulcers & $5(3.3)$ \\
Total & $\mathbf{1 5 0}(\mathbf{1 0 0 . 0 )}$ \\
\hline
\end{tabular}

\section{Antimicrobial susceptibility pattern of bacterial isolates Gram positive bacteria}

Gram positive bacteria were tested against selected 14 antibiotics. The results obtained showed that the organisms varied in their susceptibility to all the antimicrobials used.
Majority of them showed multi-resistances (resistance to two or more classes of antimicrobials). Rate of isolates resistant to ampicillin was $94 \%$, followed by penicillin G, $86.8 \%$. All isolates were $100 \%$ susceptible to vancomycin and amikacin, and showed low resistance to norfloxacin (10\%), ciprofloxacin (10\%), sulphamethoxazole trimethoprim (8.8\%) and gentamicin (8.8\%) (Table 3).

\section{Gram negative bacteria}

The susceptibility patterns of gram negative bacteria $(n=77)$ isolated from wound infections and tested against selected 11 antimicrobial agents. Rate of isolates resistant to ampicillin was $96 \%$, followed by cephalothin, 92.4\% (Table 4).

\section{Multi- drug resistance patterns of the isolates}

Multi-drug resistance (MDR) test was determined by disk diffusion method according to criteria set by CLSI 2011 against different class of antimicrobials: penicillin class (penicillin $\mathrm{G}$ and ampicillin), cephalosporin class (ceftriazone and cephalothin), glycopeptides class (vancomycin), aminoglycopeptides class (gentamicine and amikacin), Macrolides class (erythromycin), tetracycline class (tetracycline and doxycycline), fluoroquinolones class (ciprofloxacin and norfloxacin), folate pathway inhibitors (sulphamethozaxole trimthoprim) and phenicols class (chloramphenicols) for gram positive bacteria and penicillin class (ampicillin), cephalosporin class (ceftriazone and cephalothin), aminoglycosides class (gentamicin), tetracycline class (tetracycline and doxycycline), fluoroquinolones class (ciprofloxacin and norfloxacin), quinolones class (naldixic acid), folate pathway inhibitors

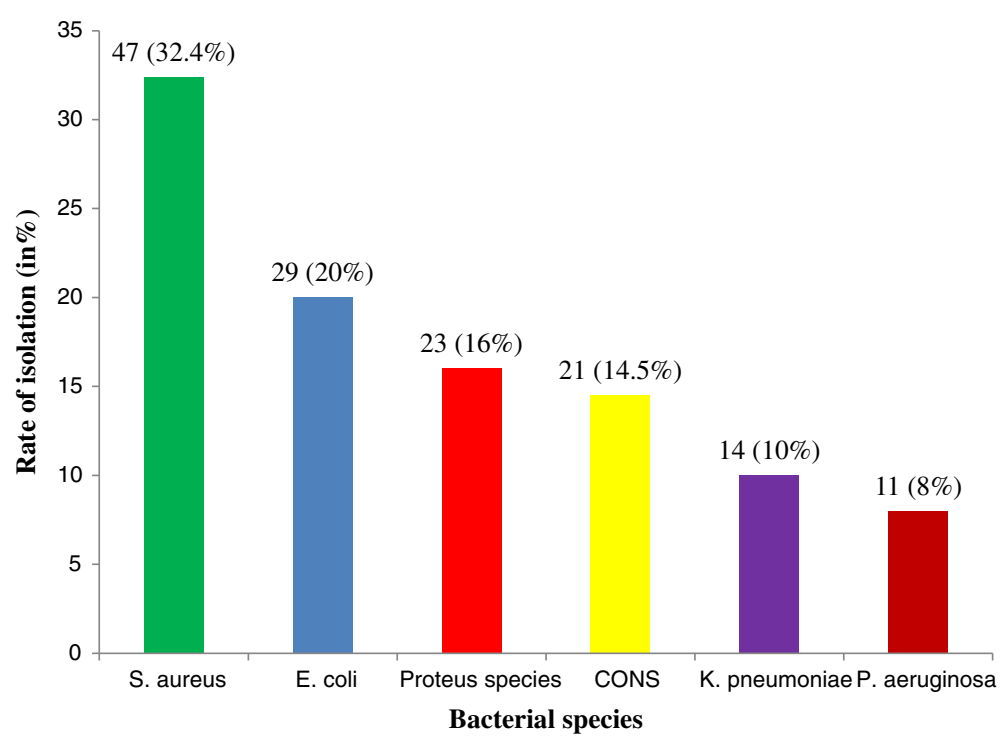

Figure 1 Percentage of bacteria isolated from patients with infected wounds at JUSH, Jimma, May-September, 2013. 
Table 3 Antibiotic susceptibility pattern of gram positive bacteria isolated from patients at JUSH, Jimma, May-September 2013

\begin{tabular}{|c|c|c|c|c|c|c|c|c|c|c|c|c|c|c|c|}
\hline \multirow[t]{2}{*}{ Isolates } & \multirow[t]{2}{*}{ RXN } & \multicolumn{14}{|c|}{ Antimicrobial agents (\%) } \\
\hline & & $\mathrm{CN}$ & VA & AK & $\mathrm{E}$ & C & SXT & NOR & $P$ & KF & CRO & TE & CIP & AP & DO \\
\hline \multirow[t]{2}{*}{ S.aures $(n=47)$} & S & $45(96)$ & $47(100)$ & $47(100)$ & $40(85.1)$ & $40(85.1)$ & $44(94)$ & $45(96)$ & $4(8.5)$ & $33(70.2)$ & $40(85.1)$ & $23(49)$ & $45(96)$ & $2(4.3)$ & $34(72.4)$ \\
\hline & $\mathrm{R}$ & $2(4)$ & - & - & $7(14.9)$ & $7(14.9)$ & $3(6)$ & $2(4)$ & $43(91.5)$ & $14(29.8)$ & $7(14.9)$ & $24(51)$ & $2(4)$ & $45(95.7)$ & $13(27.6)$ \\
\hline \multirow[t]{2}{*}{ CONS $(n=21)$} & S & $17(81)$ & $21(100)$ & $21(100)$ & $13(62)$ & $14(67)$ & $18(86)$ & $16(76.2)$ & $5(24)$ & $6(29)$ & $15(71.4)$ & $10(48)$ & $16(76.2)$ & $2(9.5)$ & $15(71.4)$ \\
\hline & R & $4(19)$ & - & - & $8(38)$ & $7(33)$ & $3(14)$ & $5(23.8)$ & $16(76)$ & $15(71)$ & $6(28.6)$ & $11(52)$ & $5(23.8)$ & $19(90.5)$ & $6(28.6)$ \\
\hline \multirow[t]{2}{*}{ Total $(n=68)$} & S & $62(91.2)$ & $68(100)$ & $68(100)$ & $53(78)$ & $54(79.4)$ & $62(91.2)$ & $61(90)$ & $9(13.2)$ & $39(57.4)$ & $55(81)$ & $33(48.5)$ & $61(90)$ & $4(6)$ & $49(72.1)$ \\
\hline & $\mathbf{R}$ & $6(8.8)$ & - & - & $15(22)$ & $14(20.6)$ & $6(8.8)$ & $7(10)$ & $59(86.8)$ & $29(42.6)$ & 13 (19) & 35 (51.5) & $7(10)$ & $64(94)$ & 19 (27.9) \\
\hline
\end{tabular}

KEY: S: Sensitive; R: Resistant; -: zero; CN: Gentamicin; V: Vancomycin; AK: Amikacin; E: Erythromycin; C: Chloramphenicol; SXT: Trimethoprim-sulphamethoxazole; NOR: Norfloxacin; P: Penicillin; KF: Cephalothin; CRO: ceftriaxone; TE: Tetracycline; CIP: Ciprofloxacin AP: Ampicillin; DO: Doxycycline. 
Table 4 Antibiotic susceptibility pattern of gram negative bacteria isolated from patients at JUSH, Jimma, MaySeptember 2013

\begin{tabular}{|c|c|c|c|c|c|c|c|c|c|c|c|c|}
\hline \multirow[t]{2}{*}{ Isolates } & \multirow[t]{2}{*}{ RXN } & \multicolumn{11}{|c|}{ Antimicrobial agents (\%) } \\
\hline & & $\overline{\mathrm{CN}}$ & C & SXT & NA & NOR & KF & CRO & $\mathrm{TE}$ & CIP & AP & DO \\
\hline \multirow[t]{2}{*}{ E.coli $(n=29)$} & $S$ & $14(48.3)$ & $10(34.5)$ & $13(45)$ & $17(59)$ & $16(55.2)$ & 0 & $11(38)$ & $6(21)$ & $19(66)$ & - & $16(55.2)$ \\
\hline & $\mathbf{R}$ & $15(51.7)$ & $19(65.5)$ & $16(55)$ & $12(41)$ & $13(44.8)$ & $29(100)$ & $18(62)$ & $23(79)$ & $10(34)$ & $29(100)$ & $13(44.8)$ \\
\hline \multirow[t]{2}{*}{ Proteus Spp $(\mathrm{n}=23)$} & $S$ & $17(74)$ & $16(70)$ & $14(61)$ & $15(65.2)$ & $20(87)$ & $3(13)$ & $8(35)$ & $6(26)$ & $19(83)$ & $2(9)$ & $13(57)$ \\
\hline & $\mathbf{R}$ & $6(26)$ & $7(30)$ & $9(39)$ & $8(34.8)$ & $3(13)$ & $20(87)$ & $15(65)$ & $17(74)$ & $4(17)$ & $21(91)$ & $10(43)$ \\
\hline \multirow[t]{2}{*}{ K. pneumonia $(n=14)$} & $\mathrm{S}$ & $5(36)$ & $2(14.3)$ & $2(14.3)$ & $7(50)$ & $11(79)$ & $2(14.3)$ & $4(29)$ & $6(43)$ & $9(64.3)$ & - & $8(57.1)$ \\
\hline & $\mathbf{R}$ & $9(64)$ & $12(85.7)$ & $12(85.7)$ & $7(50)$ & $3(21)$ & $12(85.7)$ & $10(71)$ & $8(57)$ & $5(35.7)$ & $14(100)$ & $6(42.9)$ \\
\hline \multirow[t]{2}{*}{ P. aeruginosa $(n=11)$} & $S$ & $9(82)$ & $2(18.2)$ & $3(27.3)$ & - & $11(100)$ & $\mathrm{Nt}$ & $4(36.4)$ & $2(18.2)$ & $11(100)$ & - & - \\
\hline & $\mathbf{R}$ & $2(18)$ & $9(82)$ & $8(73)$ & $11(100)$ & - & & $7(63.6)$ & $9(82)$ & - & $11(100)$ & $11(100)$ \\
\hline \multirow[t]{2}{*}{ Total $(n=77)$} & $S$ & $45(58.4)$ & $30(39)$ & $32(42)$ & $39(51)$ & $58(75.3)$ & $5(7.6)$ & $27(35.1)$ & $20(26)$ & $58(75.3)$ & $3(4)$ & $37(48.1)$ \\
\hline & $\mathbf{R}$ & 32 (41.6) & $47(61)$ & $45(58)$ & $38(49)$ & $19(24.7)$ & $61(92.4)$ & $50(64.9)$ & $57(74)$ & $19(24.7)$ & $74(96)$ & $40(51.9$ \\
\hline
\end{tabular}

KEY: S = Sensitive R = Resistant; -: zero; Nt: Not tested; CN: Gentamicin; C: Chloramphenicol; SXT: Trimethoprim-sulphamethoxazole; NOR: Norfloxacin; KF: Cephalothin; CRO: ceftriaxone; TE: Tetracycline; CIP: Ciprofloxacin AP: Ampicillin; DO: Doxycycline.

(sulphamethozaxole trimthoprim) and phenicols class (chloramphenicols) for gram negative bacterial isolates.

Multi- drug resistance was found in 123 (85\%) of the isolates. Seventy one percent $(71 \%)$ of the gram positive bacterial isolates showed multi drug resistance (two nine antimicrobial classes). Similarly, $97.4 \%$ of gram negative bacterial isolates showed MDR (against two to eight) antimicrobial classes. Furthermore, $100 \%$ of $P$. aeruginosa was resistant to two or more than two antimicrobial classes (Table 5).
Minimum inhibitory and bactericidal concentration of alternative topical agents

In vitro susceptibility of the isolated organisms to alternative topical antimicrobial agents was studied. All of the tested microorganisms were sensitive to acetic acid at a concentration of $0.5 \%(\mathrm{~V} / \mathrm{V})$ and this concentration is bactericidal when applied for 10 minute to all clinical isolates in the study. All of the isolated organisms were resistant to a concentration of $0.025 \%$ (V/V), $0.25 \%$ (V/V) of dabkin solution after incubation for 24 hrs. However, the

Table 5 Antibiogram of bacteria isolated from patients with infected wounds at JUSH, Jimma, May-September, 2013

\begin{tabular}{|c|c|c|c|c|c|c|c|}
\hline \multicolumn{8}{|c|}{ Antibiogram } \\
\hline \multicolumn{8}{|c|}{ No. (\%) of resistance } \\
\hline Organism & $\mathrm{R} 2$ & R3 & R4 & R5 & R6 & R7 & R8 \\
\hline Gram positive & $15(32)$ & $8(17)$ & $4(8.5)$ & $1(2.1)$ & $2(4.3)$ & $1(2.1)$ & 0 \\
\hline \multicolumn{8}{|l|}{$\begin{array}{l}\text { S.aures } \\
(n=47)\end{array}$} \\
\hline $\begin{array}{l}\text { CONS } \\
(n=21)\end{array}$ & $5(24)$ & $3(14.3)$ & $4(19)$ & $1(4.8)$ & 0 & $3(14.3)$ & $1(4.8)$ \\
\hline $\begin{array}{l}\text { Total } \\
(n=68)\end{array}$ & $20(29.4)$ & $11(16.2)$ & $8(12)$ & $2(3)$ & $2(3)$ & $4(6)$ & $1(1.5)$ \\
\hline Gram negative & $2(7)$ & $5(17.2)$ & $4(14)$ & $3(10.3)$ & $2(7)$ & $8(28)$ & $5(17.2)$ \\
\hline \multicolumn{8}{|l|}{$\begin{array}{l}\text { E.coli } \\
(n=29)\end{array}$} \\
\hline $\begin{array}{l}\text { Proteus Spp } \\
(n=23)\end{array}$ & $6(26.1)$ & $5(22)$ & $3(13)$ & 0 & $3(13)$ & $4(17.4)$ & $1(4.3)$ \\
\hline $\begin{array}{l}\text { K.pneumoniae } \\
(n=14)\end{array}$ & $1(7.1)$ & 0 & 0 & $3(21.4)$ & $4(29)$ & $2(14.3)$ & $3(21.4)$ \\
\hline $\begin{array}{l}\text { P.aeruginosa } \\
(n=11)\end{array}$ & $1(9.1)$ & 0 & $2(18.2)$ & 2 (18.2) & $3(27.3)$ & $3(27.3)$ & 0 \\
\hline $\begin{array}{l}\text { Total } \\
(n=77)\end{array}$ & $10(13)$ & $10(13)$ & $9(12)$ & $8(10.4)$ & $12(16)$ & $17(22.1)$ & $9(12)$ \\
\hline
\end{tabular}

$\mathrm{R} 2-\mathrm{R} 8=$ number of antimicrobial class in which a given isolate was resistant. 
solution was bactericidal at a concentration of $0.5 \%(\mathrm{~V} / \mathrm{V})$ for $58.6 \%$ of all the isolates while $100 \%$ of the isolates were killed at $1 \%(\mathrm{~V} / \mathrm{V})$ of the solution (Table 6). These concentrations were lethal to the isolates if applied for 10 minutes. The minimum inhibitory and bactericidal concentration of the solution (dabkin solution) was $0.5 \%$ and $1 \%$. The other topical agent frequently used in the study setting was 3\% Hydrogen peroxide. This solution was bactericidal to all isolated organisms from infected wound. In vitro test indicated that this solution was not bactericidal when applied for less than 10 minute.

\section{Discussion}

The incidence of wound infection was more common in males $(89.7 \%)$ than in females $(81.4 \%)$. This is in agreement with studies done in different parts of Ethiopia [7-10] and other countries [11-13]. This might be explained by the fact that traditionally, in this country mainly males are involved in occupations such as farming, construction works, transportation and industry works where the likely exposure to trauma is common.

In this study, $91.6 \%$ of culture positive wounds showed mono-microbial growth, $8.4 \%$ showed poly-microbial growth and $12.7 \%$ had no bacterial growth. Similarly high percentage of mono-microbial growth was reported in India (86-100\%) and Pakistan (98\%) [14-17].

In our study, S. aureus (32.4\%) and E. coli (20\%) were the predominant organisms isolated from wound infections. A number of reports done previously on wound infection from Ethiopia and different parts of the world indicated that $S$. aureus and $E$. coli were the most frequent isolates [18-21]. The high prevalence of $S$. aureus infection may be because it is an endogenous source of infection. Infection with this organism may also be due to contamination from the environment e.g. contamination of surgical instruments. With the disruption of natural skin barrier S.aureus, which is a common bacterium on surfaces, easily find their way into wounds.

Coagulase Negative Staphylococci (CONS) accounted for $14.5 \%$ of the organisms isolated from wounds in this study. This is not unexpected since the organism is a commensal or normal flora on the skin. Several investigations have reported these organisms as common contaminants of wounds [9,20].

Resistance to the selected antimicrobials was very high. The average resistance of the isolates to all the antibiotics in gram positive cocci was (99\%) and gram negative bacilli (100\%). This is similar to the study done in Ethiopia with average resistance of gram positive cocci isolates (100\%)

Table 6 Minimum inhibitory concentrations of alternative topical agents against bacterial isolates from patients, JUSH, May-September 2013

\begin{tabular}{|c|c|c|c|c|c|}
\hline Antimicrobial agents & Isolates & $0.025 \%(\mathrm{~V} / \mathrm{V})$ & $0.25 \%(\mathrm{~V} / \mathrm{V})$ & $0.5 \%(\mathrm{~V} / \mathrm{V})$ & $1 \%(V / V)$ \\
\hline \multirow[t]{7}{*}{ Dabkin solution } & S. aureus & All isolates were resistant & All isolates were resistant & $35(74.5 \%)$ & $47(100 \%)$ \\
\hline & CONS & & & $15(71.4 \%)$ & $21(100 \%$ \\
\hline & E.coli & & & $8(28 \%)$ & $29(100 \%)$ \\
\hline & Proteus Spp & & & $15(65.2 \%)$ & $23(100 \%)$ \\
\hline & K.pneumoniae & & & $10(71.4 \%)$ & $14(100 \%)$ \\
\hline & P.aeruginosa & & & $2(18.2 \%)$ & $11(100 \%)$ \\
\hline & Total & & & 85 (59\%) & 145 (100\%) \\
\hline \multirow[t]{7}{*}{ Acetic acid } & & & $0.5 \%(\mathrm{~V} / \mathrm{V})$ & & \\
\hline & S. aureus & & 47 (100\%) & & \\
\hline & CONS & & $21(100 \%)$ & & \\
\hline & E.coli & & $29(100 \%)$ & & \\
\hline & Proteus Spp & & $23(100 \%)$ & & \\
\hline & K.pneumoniae & & $14(100 \%)$ & & \\
\hline & P.aeruginosa & & $11(100 \%)$ & & \\
\hline \multirow[t]{7}{*}{ Hydrogen peroxide } & & & $3 \%(W / V)$ & & \\
\hline & S. aureus & & 47 (100\%) & & \\
\hline & CONS & & $21(100 \%)$ & & \\
\hline & E.coli & & $29(100 \%)$ & & \\
\hline & Proteus Spp & & $23(100 \%)$ & & \\
\hline & K.pneumoniae & & $14(100 \%)$ & & \\
\hline & P.aeruginosa & & $11(100 \%)$ & & \\
\hline
\end{tabular}


and gram negative bacilli isolates (95.5\%) respectively [20]. The overall multiple drug resistance (two and above antimicrobial classes) of the isolates in this study was $85 \%$ which was in line with previous study done in different parts of the world $[8,19,22]$. High resistance of the isolates to antibiotics may be due to practicing self medication, lack of diagnostic laboratory services or unavailability of guideline regarding the selection of drugs thereby which lead to inappropriate use of antibiotics.

In the determination of the susceptibility of $S$. aureus on fifteen selected antibiotics by disk diffusion technique showed that $S$. aureus tend to be resistant to a wider spectrum of antibiotics. In this studies S.aureus was highly resistance to ampicillin (95.7\%), penicillin (91.5\%) and tetracycline (51\%). This was consistent with study done in Ethiopia [19,20] and elsewhere [4,11,14,23]. The same isolate was highly sensitive to amikacin (100\%), vancomycin (100\%), ciprofloxacin (96\%), norfloxacin (96\%) and gentamicin (96\%). This finding is in agreement with the work of Bess LJ. et al., Bibi S. et al., Shamsuzzaman et al., Gelaw A. et al., Gautam R et al., and Shriyan A. et al., [7,15,23-26], who reported that clinical Staphylococci are $100 \%$ sensitive to vancomycin and $[24,27,28]$ to amikacin. In this study, coagulase negative Staphylococci were $100 \%$ sensitive to amikacin and vancomycin, sulphamethoxazole trimethoprim (86\%), gentamicin (83\%) and ciprofloxacin (76.2\%). This finding was comparable with the previous studies done in different parts of the world $[11,28]$. The same organism was remarkably resistance to ampicillin (90.5\%), penicillin (76\%), cephalothin (71\%) and tetracycline (52\%). This finding was comparable with study done in the same country $[20,29,30]$ and in other parts of the world $[4,11,14,31]$. Remarkable susceptibility of gram positive bacteria to vancomycin, amikacin and aminoglycosides (gentamicin) may be due to lesser use of these antibiotics as a result of their less availability, cost and toxic effect respectively.

In this study, $100 \%$ of the E.coli isolates were resistant to cephalothin, ampicillin (96.6\%), tetracycline (79\%), chloramphenicol (65.5\%), ceftriaxone (62\%), sulphamethoxazole trimethoprim (55\%) and gentamicin (51.7\%). Sensitivity pattern of E.coli in our study as compared to others were ciprofloxacin $(65.5 \%)$ and naldixic acid (59\%) [8,19,28,29]. So, reduced antibiotic sensitivity pattern noted for $E$. coli suggests its importance for hospital acquired infection.

K. pneumoniae was $100 \%$ resistance to ampicillin, $85.7 \%$ in chloramphenicol, sulphamethoxazole trimethoprim and cephalothin, (71\%) in ceftriaxone however it indicates low resistance to ciprofloxacin (35.7\%) and doxycycline. This was in consistence with the study done in Ethiopia $[7,8,20,30]$. Proteus species were resistance to ampicillin (91\%), cephalothin (87\%), tetracycline $(73.9 \%)$ and ceftriaxone (65\%). The isolates were sensitive to ciprofloxacin (83\%) and gentamicin (74\%). This was compared to previous studies done in the country $[8,29,30]$ and elsewhere $[25,32,33]$. Most of the gram negative bacteria isolated were resistant to ampicillin, cephalothin, tetracycline and chloramphenicol. This may be due to the antibiotics having been in use for much longer time and their oral route of administration that affects their rate of absorption into blood stream. Some of them were used as prophylaxis therefore increasing their use in patients. Over use of antibiotics contributes to organisms developing resistance.

In our study $P$. aeruginosa showed reduced sensitivity to commonly used antibiotics like ampicillin, doxycycline, naldixic acid, and tetracycline, except ciprofloxacin, norfloxacin (100\%), and gentamicin (82\%). Ciprofloxacin and norfloxacin has been stated to be the most potent oral drug available for the treatment of $P$. aeruginosa infections. This report is in conformity with the result of other study in which ciprofloxacin recorded the least resistance (6.2-24\%) to P. aeruginosa isolates from wound infection $[20,29,34]$. It is undoubtable that at the present time, the oral drug ciprofloxacin and injection gentamicin are the most effective antibiotics against $P$. aeruginosa involved in wound infection relative to most other commonly used drugs. Pseudomonas resistant to third generation cephalosporins (ceftriaxone 63.6\%) is real treat. In fact, the irrational and inappropriate use of antibiotics is responsible for the development of resistance of Pseudomonas to antibiotic monotherapy. The incidence of $P$. aeruginosa in wound infection among admitted patient is becoming more serious in developing countries because of lack of general hygienic conditions, production of low quality antiseptics and medicinal solutions for treatment [11].

The use of acetic acid has been reported from time to time as a topical agent for the treatment of Pseudomonal infections and in most reports has been used for burns and superficial infection. Topical use of acetic acid at concentrations between 0.5 to $5 \%$ eliminated $P$. aeruginosa from the burns and soft tissue wounds of 14 out of the 16 patients within two weeks treatment [35]. Even though, the former study was in vivo the same result was obtained in vitro in this study in which $0.5 \%$ acetic acid was bactericidal for $P$. aeruginosa.

Acetic acid had high bactericidal effect than dabkin solution tested at $0.5 \%$ concentration against clinical isolates obtained from infected wound. Acetic acid was bactericidal at $0.5 \%$ concentration, which can be used clinically because it was highly diluted and non toxic. Other study done on acetic acid antimicrobial effect and toxic effect indicate that this concentration of acetic acid was non toxic, easily available [36]. Furthermore in this study $0.5 \%$ acetic acid was bactericidal for gram positive (S.aureus and CONS) and gram negative bacilli (E. coli, K. pneumoniae, Proteus spp and $P$. aeruginosa). Majority of the study done so far used this topical agent for the treatment of P.aeruginosa in the concentration interval of 0.5-5\% [35]. 
Study have been done on sodium hypochlorite solutions to determine its bactericidal and wound-healing properties with concentrations of $0.25 \%, 0.025 \%$, and $0.0125 \%$ at 5-, 10-, 15-, and 30-minute intervals indicated that bactericidal effects were observed for concentrations as low as $0.025 \%$. While, tissue toxicity, both in vitro and in vivo, was observed at concentrations of $0.25 \%$ but not at a concentration of $0.025 \%$ [37]. However in this study the solution was not bactericidal at concentration of $0.025 \%$ and $0.25 \%$, this may be due to increased resistance of bacteria to the solution; this solution was bactericidal in our setting at the concentration of $0.5 \%$ and $1 \%$.

Antimicrobial activity and effectiveness of a combination of sodium hypochlorite and hydrogen peroxide in killing and removing $P$. aeruginosa biofilms from surfaces showed either a significant reduction or complete removal of biofilm material after a 5 min exposure to the mixed sodium hypochlorite and hydrogen peroxide solution [38]. Hydrogen peroxide in the current study setting was bactericidal to all isolates when exposed to the isolates for the minimum of 10 minutes otherwise $20 \%$ of the total isolates were resistance when applied for less than 10 minutes.

\section{Conclusion}

The most common isolate in wound infection was $S$. aureus followed by E. coli, Proteus species, CONS and K. Pneumoniae. These isolates showed high frequency of resistance to ampicillin, penicillin, cephalothin and tetracycline. Seventy one percent (71\%) and $97.4 \%$ of Gram positive and Gram negative isolates showed MDR respectively with overall MDR of $85 \%$. On in vitro sensitivity testing, acetic acid at a concentration of $0.5 \%(\mathrm{~V} / \mathrm{V})$, dabkin solution at concentration of $1 \%(\mathrm{~V} / \mathrm{V})$ and $3 \%$ hydrogen peroxide were bactericidal against all clinical isolates.

\section{Competing interests}

The authors declare that they have no competing interests.

\section{Authors' contributions}

MM, TS and AA participated in design, laboratory analysis, interpretation of the data and write up of the manuscript. All the authors read and approved the final version.

\section{Acknowledgements}

The authors would like to acknowledge Medical Laboratory Sciences and Pathology Department, Jimma University for allowing its laboratory facilities.

\section{Funding}

The study was funded by Jimma University, Ethiopia.

\section{Author details}

'Department of Medical Laboratory Science, Arba Minch University, Arba Minch, Ethiopia. ${ }^{2}$ Department of Medical Laboratory Science and Pathology, Jimma University, Jimma, Ethiopia.
Received: 8 January 2014 Accepted: 7 April 2014

Published: 14 April 2014

\section{References}

1. Ndip RN, Takang AEM, Echakachi CM, Malongue A, Akoachere J-FTK: In vitro antimicrobial activity of selected honeys on clinical isolates of Helicobacter pylori. Afr Health Sci 2007, 7(4):228-231.

2. Dai T, Huang Y-Y, Sharma SK, Hashmi JT, Kurup DB, Hamblin MR: Topical antimicrobials for burn wound infections. Recent Pat Antiinfect Drug Discov 2010, 5(2):124-151.

3. Kotz P, Fisher J, McCluskey P, Hartwell SD, Dharma H: Use of a new silver barrier dressing, ALLEVYN Ag in exuding chronic wounds. Int Wound J 2009, 6:186-194.

4. Taiwo S, Okesina A, Onile B: In vitro antimicrobial susceptibility pattern of bacterial isolates from wound infections in University of llorin Teaching Hospital. Afr J Clin Exp Microbiol 2002, 3(1):6-10.

5. Al-Waili NS, Salom K, Al-Ghamdi AA: Honey for wound healing, ulcers, and burns. TheScientificWorldJOURNAL 2011, 11:766-787.

6. Cooper RA, Molan PC, Harding KG: The sensitivity to honey of Gram-positive cocci of clinical significance isolated from wounds. J App Microbiol 2002, 93:857-863.

7. Gelaw A: Isolation of bacterial pathogens from patients with postoperative surgical site infections and possible sources of infections at University of Gondar Hospital, Northwest Ethiopia. 2011, http://etd.aau. edu.et/dspace/bitstream/123456789/2139/1/ASCHALEW\%20GELAW.pdf.

8. Biadglegne F, Abera B, Alem A, Anagaw B: Bacterial isolates from wound infection and their antimicrobial susceptibility pattern in Felege Hiwot Referral Hospital, North West Ethiopia. Ethiop J Health Sci 2009, 19(3):173-178

9. Tekie K: Surgical wound infection in Tikur Anbessa Hospital with special emphasis on Pseudomonas aeruginosa. 2008, http://etd.aau.edu.et/dspace/ bitstream/123456789/2621/1/KASSAYE\%20TEKIE..pdf.

10. Taye M: Wound infection in Tikur Anbessa hospital, surgical department. Ethiop Med J 2005, 43(3):167-174.

11. Goswami N, Trivedi HR, Goswami APP: Antibiotic sensitivity profile of bacterial pathogens in postoperative wound infections at a tertiary care hospital in Gujarat, India. J Pharm Pharm 2011, 2(3):158-164

12. Ohalete CN, Obi RK, EmeaKoroha MC: Bacteriology of different wound infection and their antimicrobial susceptibility patterns in Imo state Nigeria. World J Pharm Pharm Sci 2012, 1(3):1155-1172.

13. Amoran OE, Sogebi AO, Fatugase OM: Rates and risk factors associated with surgical site infections in a tertiary care center in South-Western Nigeria. Int J Trop Dis Health 2013, 3(1):25-36.

14. Suchitra JB, Lakshmidevi N: Surgical site infections: assessing risk factors, outcomes and antimicrobial sensitivity patterns. Afr J Microbiol Res 2009 3(4):175-179.

15. Bibi S, Channa GA, Siddiqui TR, Ahmed W: Pattern of bacterial pathogens in postoperative wounds and their sensitivity patterns. J Surg Pak (Int) 2012, 17(4):164-167.

16. Sanjay KR, Prasad MNN, Vijaykumar GS: A study on isolation and detection of drug resistance gram negative bacilli with special importance to post operative wound infection. J Microbiol Antimicrob 2010, 2(6):68-75.

17. Basu S, Ramchuran PT, Bali ST, Gulati A, Shukla V: A prospective, descriptive study to identify the microbiological profile of chronic wounds in outpatients. Ostomy Wound Manage 2009, 55(1):14-20.

18. Bhatt C, Lakhey M: The distribution of pathogens causing wound infection and their antibiotic susceptibility pattern. $J$ Nepal Health Res Council 2006, 5(1):22-26.

19. Mulu A, Moges F, Tessema B, Kassu A: Patterns and multiple drug resistance of bacterial pathogens at university of Gondar teaching hospital. Northwest Ethiopia Ethiop Med J 2006, 44(2):125-131.

20. Mulu W, Kibru G, Beyene G, Damtie M: Postoperative nosocomial infections and antimicrobial resistance pattern of bacteria isolates among patients admitted at Felege Hiwot Referral Hospital, Bahirdar. Ethiopia Ethiop J Health Sci 2012, 22(1):7-18.

21. Emele F, Izomoh M, Alufohai E: Microorganisms Associated With Wound Infection In Ekpoma. Nigeria. West Afr J Med 1999, 18(2):97-100.

22. Bayram Y, Parlak M, Aypak C, Bayram I: Three-year review of bacteriological profile and anti-biogram of burn wound isolates in Van, Turkey. Int J Med Sci 2013, 10(1):19-23. 
23. Shamsuzzaman A, Sirajee A, Rahman M, Miah A, Hossain M: Pattern of aerobic bacteria with their drug susceptibility of surgical inpatients. Mymensingh Med J 2003, 12(2):98-103.

24. Gautam R, Acharya A, Nepal HP, Shrestha S: Antibiotic susceptibility pattern of bacterial isolates from wound infection in Chitwan Medical College Teaching Hospital, Chitwan, Nepal. IJBAR 2013, 4(4):248-252.

25. Bessa LJ, Fazii P, Giulio MD, Cellini L: Bacterial isolates from infected wounds and their antibiotic susceptibility pattern: some remarks about wound infection. Int Wound J 2013, doi:10.1111/iwj.12049.

26. Shriyan A, Sheetal R, Nayak N: Aerobic micro-organismsin post-operative wound infections. J Clin Diag Res 2010, 4:3392-3396.

27. Mahmood A: Bacteriology of surgical site infections and antibiotic susceptibility pattern of the isolates at a tertiary care hospital in Karachi. JPMA 2000, 50:256.

28. Manikandan C, Amsath A: Antibiotic susceptibility of bacterial strains isolated from wound infectionpatients in Pattukkottai, Tamilnadu, India. Int I Curr Microbiol App Sci 2013, 2(6):195-203.

29. Abraham Y, Wamisho BL: Microbial susceptibility of bacteria isolated from open fracture wounds presenting to the err of black-lion hospital, Addis Ababa University, Ethiopia. Afr J Microbiol Res 2009, 3(12):939-951.

30. Endalafer N: Bacterial Nosocomial infections and their antimicrobial susceptibility patterns in surgicalwards and surgical Intensive care unit (SICU) of Tikur Anbessa University Hospital Addis Ababa, Ethiopia. 2008

31. Islam MA, Alam MM, Choudhury ME, Kobayashi N, Ahmed MU: Determination of minimum inhibitory concentration (MIC) ofcloxacillin for selected isolates of methicillin resistant Staphylococcus aureus (MRSA) with their antibiogram. Bangl J Vet Med 2008, 6(1):121-126.

32. Feglo PK, Gbedema SY, Quay SNA, Adu-Sarkodie Y, Opoku-Okrah C: Occurrence, species distribution and antibiotic resistance of Proteusisolates: a case study at the Komfo Anokye Teaching Hospital (KATH) in Ghana. IJPSR 2010, 1(9):347-352.

33. Lema T, Woldeamanuel $Y$, Asrat D, Hungnaw M, Baraki A, Kebede $Y$, Yamuah $L$, Aseffa A: The pattern of bacterial isolates and drug sensitivities of infected ulcers in patients with leprosy in ALERT, Kuyera and Gambo Hospitals, Ethiopia. Lepr Rev 2012, 83:40-51.

34. Manyahi J: Bacteriological spectrum of post-operative wound infections and their antibiogram in a tertiary hospital, Dar es Salaam, Tanzania. In Muhimbili University of Health and Allied Sciences, PhD thesis. 2012.

35. Nagoba B, Wadher B, Kulkarni P, Kolhe S: Acetic acid treatment of pseudomonal wound infections. Eur J Gen Med 2008, 5(2):104-106.

36. Juma IM, Yass Ha S, Al-Jaberi FH: Comparison between the effect of acetic acid and salicylic acid in different concentrations on Pseudomonas aeruginosa isolated from burn wound infection. 2006.

37. Heggers JP, Sazy JA, Stenberg BD, Strock LL, McCauley RL, Herndon DN, Robson MC: Bactericidal and wound-healing properties of sodium hypochlorite solutions: the 1991 Lindberg Award. J Burn Care Rehabil 1991, 12(5):420-424.

38. DeQueiroz G, Day D: Antimicrobial activity and effectiveness of a combination of sodium hypochlorite and hydrogen peroxide in killing and removing Pseudomonas aeruginosa biofilms from surfaces. J Appl Microbiol 2007, 103(4):794-802.

doi:10.1186/1476-0711-13-14

Cite this article as: Mama et al:: Antimicrobial susceptibility pattern of bacterial isolates from wound infection and their sensitivity to alternative topical agents at Jimma University Specialized Hospital, South-West Ethiopia. Annals of Clinical Microbiology and Antimicrobials 2014 13:14.

\section{Submit your next manuscript to BioMed Central and take full advantage of:}

- Convenient online submission

- Thorough peer review

- No space constraints or color figure charges

- Immediate publication on acceptance

- Inclusion in PubMed, CAS, Scopus and Google Scholar

- Research which is freely available for redistribution 